ORIGINAL ARTICLE

\title{
Cell cycle regulation in patients with intestinal metaplasia at the gastro-oesophageal junction
}

\author{
N J Trudgill, S K Suvarna, J A Royds, S A Riley
}

J Clin Pathol: Mol Pathol 2003;56:313-317

See end of article for authors' affiliations

.....................

Correspondence to: Dr S A Riley, Department of Gastroenterology, Northern General Hospital, Sheffield S5 7AU, UK; stuart.riley@ sth.nhs.uk

Accepted for publication 20 July 2003

Background/Aims: The incidence of oesophageal adenocarcinoma is increasing rapidly and this may be related to the presence of intestinal metaplasia (IM) at the gastro-oesophageal junction (GOJ). Recent studies have distinguished two subtypes of IM at the GOJ: short segment Barrett's oesophagus (SSBO) and $I M$ at a normal squamo-columnar junction (IMNSCJ). Because abnormal expression of cell cycle regulators is common in cancer and precancerous states, cell cycle regulation was studied in patients with IM at the GOJ.

Methods: Biopsy samples and resected materials were identified from patients with SSBO (10), IMNSCJ (14), a normal SCJ with (14) and without (12) inflammation, conventional Barrett's oesophagus (BO) (12), and oesophageal adenocarcinoma (12). Sections were stained with antibodies to p21, p27, p53, Ki67, cyclin D1, and c-erbB2 and were assessed independently by two observers, using predetermined criteria. Results: Patients with oesophageal adenocarcinoma showed high expression of c-erbB2, p53, p27, and Ki67. Patients with BO showed expression of c-erbB2 but little expression of other markers. Greatly increased expression of cyclin D1 was seen in patients with IMNSCJ. The expression of all other markers was similar in patients with IMNSCJ and those with SSBO. Cyclin DI and c-erbB-2 were coexpressed in patients with SSBO and IMNSCJ, and their expression was associated with the presence of p53 and p21. Conclusions: Although the proposed aetiologies of SSBO (gastro-oesophageal reflux) and IMNSCJ (Helicobacter pylori infection) differ, the cell cycle response is similar and both may have malignant potential.

$\mathrm{T}$ he incidence of adenocarcinoma of the oesophagus and gastro-oesophageal junction is rising rapidly, ${ }^{12}$ and Barrett's oesophagus with intestinal metaplasia is the major risk factor. Up to $86 \%$ of oesophageal adenocarcinomas are associated with Barrett's mucosa, ${ }^{3}$ and endoscopic follow up of patients with Barrett's oesophagus has suggested an annual risk of adenocarcinoma as high as $2.8 \%{ }^{4}$

However, conventional Barrett's oesophagus is present in only $1 \%$ of unselected patients with dyspepsia, whereas biopsies from the gastro-oesophageal junction, in the absence of conventional Barrett's oesophagus, show intestinal metaplasia in up to $20 \%$ of patients attending for diagnostic gastroscopy. ${ }^{56}$ This histological change may be found either in short segments or tongues of gastric-like mucosa in the oesophagus (short segment Barrett's oesophagus; SSBO), when it is associated with reflux symptoms and oesophagitis, or at a normal squamo-columnar junction (SCJ) (intestinal metaplasia at a normal SCJ; IMNSCJ), when it is associated with Helicobacter pylori infection. ${ }^{7}$ The malignant potential of these conditions is unknown, but adenocarcinomas are known to arise in tongues of gastriclike mucosa, ${ }^{8}$ and the presence of dysplasia in patients with intestinal metaplasia at the gastro-oesophageal junction and its development and progression to carcinoma on endoscopic follow up has also been noted. ${ }^{10}{ }^{11}$

"Endoscopic follow up of patients with Barrett's oesophagus has suggested an annual risk of adenocarcinoma as high as $2.8 \% "$

Altered expression of cell cycle proteins has been reported in a variety of neoplastic processes, including those within the oesophagus. ${ }^{12-19}$ Therefore, using tissue immunohistochemistry, we have studied samples from patients with intestinal metaplasia at the gastro-oesophageal junction, samples from patients with Barrett's oesophagus and oesophageal adenocarcinoma complicating Barrett's oesophagus, and appropriate control samples.

\section{METHODS}

\section{Subjects}

Samples from six groups of subjects were studied. Patients with a normal SCJ were identified and subdivided into two groups: those with $(n=14)$ and without $(n=12)$ inflammation (according to the presence or absence of neutrophil polymorphs in the lamina propria). Patients with intestinal metaplasia at the gastro-oesophageal junction were identified and subdivided into two groups: those with a normal SCJ $(\mathrm{n}=14)$ and those with SSBO $(\mathrm{n}=10)$. A further group with conventional Barrett's oesophagus $(n=12)$ was studied. Patients with dysplasia were excluded from our study. A final group comprised patients with oesophageal adenocarcinoma associated with oesophageal columnar epithelium with intestinal metaplasia $(\mathrm{n}=12)$.

For the purpose of our study, a normal SCJ was defined as one that was coincident with the proximal limit of the gastric folds. Barrett's oesophagus was defined by the combination of the endoscopic appearance of at least $3 \mathrm{~cm}$ of gastric-like mucosa extending above the proximal margin of the gastric folds, together with the presence of intestinal metaplasia. Those with a short segment $(0.5$ to $2.5 \mathrm{~cm})$ of gastric-like mucosa and those with tongues of gastric-like mucosa

Abbreviations: CDK, cyclin dependent kinase; IMNSCJ, intestinal metaplasia at a normal squamo-columnar junction; PBS, phosphate buffered saline; SCJ, squamo-columnar junction; SSBO, short segment Barrett's oesophagus 
extending at least $0.5 \mathrm{~cm}$ above the SCJ and the presence of intestinal metaplasia were grouped together as SSBO.

\section{Section preparation and immunohistochemical staining}

Sections ( $4 \mu \mathrm{m}$ thick) were cut and mounted on 3,3aminopropyltriethoxysilane (Sigma, Poole, Dorset, UK) coated slides. The sections were dewaxed in xylene, then rehydrated through two washes of absolute alcohol and one wash each of $95 \%$ and $70 \%$ alcohol. The tissue was not allowed to dry out.

Endogenous peroxidase activity was blocked by incubation with $2 \%$ hydrogen peroxide in methanol for 20 minutes, followed by a rinse in tap water for two minutes. With the exception of the sections stained for c-erbB2, the sections were then microwaved in $0.01 \mathrm{M}$ trisodium citrate for two periods of five minutes each on high power, and then rinsed in water for a further two minutes.

Sections were then incubated with 1.5\% normal horse serum diluted in phosphate buffered saline (PBS) at $\mathrm{pH} 7.3$ (BDH Chemicals, Atherstone, UK) for 30 minutes at room temperature, before incubation overnight at $4^{\circ} \mathrm{C}$ in the primary antihuman antibody diluted in PBS. The following antibodies were used: anti-p21 (Calbiochem, Beeston, UK; l/ 100 dilution), anti-p27 (gift of Dr X Lu, Ludwig Institute for Cancer, London, UK; 1/100 dilution), anti-p53 (clone DO7; NovoCastra, Newcastle, UK; 1/100 dilution), anti-Ki67 (clone MIB-1; Immunotech, Marseille, France; 1/100 dilution), anticyclin DI (Santa Cruz, Devizes, UK; 1/100 dilution), and antic-erbB2 (clone CB11; NovoCastra; 1/40 dilution).

The next day, sections were rinsed in PBS for five minutes and bound antibody was detected using the Vector $\mathrm{ABC}$ system (Vector Laboratories UK Ltd, Peterborough, UK) with diaminobenzidine hydrochloride as chromogen. Sections were rinsed in water and counterstained with Gill's haematoxylin, dehydrated through a graded series of alcohols (75\%, 95\%, and two washes with absolute alcohol), and mounted.

Breast or colorectal tumour samples, with established expression of the antigen under study, were used as positive controls, and omission of the primary antibody was used as a negative control. Helicobacter status was assessed in antral biopsies stained by the Gimenez method.

\section{Section scoring}

Sections were scored, independently, by two pathologists using four grades, namely: 0 (less than $5 \%$ of cells stained), + (5-33\% of cells stained), $++(33-66 \%$ of cells stained), and $+++(66-100 \%$ of cells stained). Membranous staining was scored for c-erbB2 and nuclear staining for all other antibodies. Sections that were scored differently were reviewed by all four authors and a consensus score was agreed.

\section{Statistical analysis}

Data are expressed as median (range) unless otherwise stated. When comparing antibody associations within groups all results that were scored + or more were considered positive and were analysed using the $\chi^{2}$ test with Yates' correction. For between group comparisons, grades 0 to $3+$ were analysed using the Mann-Whitney U test.

\section{RESULTS}

\section{Subjects}

Table 1 shows the demographic data of the six groups. Patients with Barrett's oesophagus, with oesophageal adenocarcinoma, and with IMNSCJ were older than patients with a normal SCJ, with or without inflammation $(p<0.05)$. There were no significant sex differences between the groups. As would be anticipated, patients with Barrett's oesophagus were more likely to be taking proton pump inhibitors than those with IMNSCJ $(\mathrm{p}=0.05)$. Helicobacter pylori was far more common in patients with IMNSCJ or a normal SCJ with inflammation than in patients with a normal SCJ without inflammation $(\mathrm{p}<0.001)$.

\section{Immunohistochemistry}

Table 2 shows the expression of the six antibodies in each of the six groups.

In patients with a normal SCJ, proliferative gene expression was low. Patients with inflammation at the SCJ had increased expression of Ki67 and a modest increase in p27 and p21, but these changes were not significant. Within these combined groups, an association was found between p27 and cyclin Dl expression $(\mathrm{p}=0.04)$.

Patients with conventional Barrett's oesophagus had higher expression of c-erbB2 than those with a normal SCJ $(\mathrm{p}=0.04)$. Surprisingly, the expression of proliferative markers was low.

However, patients with oesophageal adenocarcinoma showed high c-erbB2 expression, together with increased p53 expression, compared with patients with a normal SCJ $(p<0.01)$, SSBO/IMNSCJ $(p=0.02)$, or Barrett's oesophagus $(\mathrm{p}<0.01)$. p21 expression appeared to be increased, although the results were not significant. Patients with adenocarcinoma also showed higher expression of p27 than did those with a normal SCJ $(p=0.02)$ or Barrett's oesophagus $(\mathrm{p}<0.01)$, and increased Ki67 expression compared with patients with a normal SCJ $(p=0.02)$, SSBO/IMNSCJ $(p<0.01)$, or Barrett's oesophagus $(\mathrm{p}=0.03)$.

In patients with IMNSCJ and SSBO, c-erbB2 expression was similar to that seen in patients with Barrett's oesophagus, but p27 expression was significantly increased (combined data from patients with SSBO and IMSCJ compared with patients with Barrett's oesophagus; $\mathrm{p}=0.02$ ). When the two groups were compared, greatly increased expression of cyclin Dl was found in patients with IMNSCJ than in those with SSBO $(p=0.05)$. However, there were no other significant differences in expression scores between these two groups.

In the combined SSBO and IMNSCJ group, cyclin DI and c-erbB2 expression appeared to be associated. Seventy nine per cent of sections that were cyclin Dl positive were also c-erbB2 positive, whereas $22 \%$ of cyclin D1 negative sections were c-erbB2 positive $(\mathrm{p}=0.03)$. Combined cyclin D1 and c-erbB2 expression paralleled the expression of both p53 and p21. Sixty per cent of cyclin D1 positive sections were p53 positive, whereas only $11 \%$ of cyclin Dl negative sections were $\mathrm{p} 53$ positive $(\mathrm{p}=0.05)$. Sixty nine per cent of c-erbB2 positive sections were also p21 positive, but only $20 \%$ of c-erbB2 negative sections were $\mathrm{p} 21$ positive $(\mathrm{p}=0.05)$.

\section{DISCUSSION}

Barrett's oesophagus is the principal risk factor for the development of oesophageal adenocarcinoma. ${ }^{20}$ However, adenocarcinoma may also arise in short segments of gastric-like mucosa with intestinal metaplasia that fail to reach conventional criteria for Barrett's oesophagus. ${ }^{8} 9$ Recent studies have distinguished two subtypes of intestinal metaplasia at the gastro-oesophageal junction: SSBO and IMNSCJ. Preliminary natural history data confirm that dysplasia and carcinoma can develop in such segments, ${ }^{10} 11$ but the risk of malignant transformation in comparison with patients with conventional Barrett's oesophagus has not been assessed.

In other parts of the gastrointestinal tract, evidence of stepwise oncogene activation with loss of tumour suppressor 


\begin{tabular}{|c|c|c|c|c|c|c|}
\hline & $\begin{array}{l}\text { Normal SCJ no } \\
\text { inflammation } \\
(n=12)\end{array}$ & $\begin{array}{l}\text { Normal SCJ with } \\
\text { inflammation } \\
(n=14)\end{array}$ & $\begin{array}{l}\text { BO } \\
(n=12)\end{array}$ & $\begin{array}{l}\text { OAC } \\
(n=12)\end{array}$ & $\begin{array}{l}\text { SSBO } \\
(n=10)\end{array}$ & $\begin{array}{l}\text { IMNSCJ } \\
(n=14)\end{array}$ \\
\hline Age (years) & $46(25-72)$ & $48(26-66)$ & $66(47-78)$ & $65(55-80)$ & $58(29-90)$ & $59(35-81)$ \\
\hline Male & $58 \%$ & $50 \%$ & $75 \%$ & $67 \%$ & $30 \%$ & $36 \%$ \\
\hline $\begin{array}{l}\text { Length of } \\
\text { columnar } \\
\text { segment }(\mathrm{cm})\end{array}$ & $0(0-1)$ & $0(0-2)$ & $5(3-10)$ & - & $1(1-2)$ & 0 \\
\hline $\begin{array}{l}\text { Helicobacter } \\
\text { pylori infection }\end{array}$ & $0 \%$ & $86 \%$ & - & - & $40 \%$ & $79 \%$ \\
\hline $\begin{array}{l}\text { Proton pump } \\
\text { inhibitor } \\
\text { treatment }\end{array}$ & $17 \%$ & $29 \%$ & $58 \%$ & - & $20 \%$ & $14 \%$ \\
\hline
\end{tabular}

gene function is seen during the progression from normal, through dysplastic states, to frank neoplasia. Therefore, our study chose to consider cell cycle protein expression in the groups described above by means of immunohistochemistry in an attempt to clarify whether SSBO, IMNSCJ, and Barrett's oesophagus have a similar pathophysiology and malignant potential.

The markers used in our study examine several different aspects of the cell cycle. p53 is expressed in response to DNA damage and regulates cell division by preventing progression from G1 to $S$ phase, allowing DNA repair to take place. ${ }^{21}$ p21 is a cyclin dependent kinase (CDK) inhibitor induced by wild-type p53 to downregulate cell division. ${ }^{22}$ p27 is also a CDK inhibitor and regulates the cell cycle, but its expression is not dependent on p53. ${ }^{23}$ Cyclin $\mathrm{Dl}$, in collaboration with CDKs, facilitates progression through the Gl phase of the cell cycle and may act as an oncogene. ${ }^{24} \mathrm{Ki} 67$ is a nuclear antigen present in proliferating but not resting cells. ${ }^{21}$ C-erbB2 is homologous to the epidermal growth factor receptor and is regarded as a protooncogene, increasing cellular proliferation. ${ }^{25}$

"The presence of inflammation was associated with an increase in Ki67, indicating increased cellular proliferation and a modest increase in cell cycle regulators: p53, $\mathrm{p} 21$, and $\mathrm{p} 27^{\prime \prime}$

Previous publications have revealed abnormalities of several markers of the cell cycle in relation to progression from intestinal metaplasia to dysplasia and adenocarcinoma in patients with Barrett's oesophagus. Mutations of p53 have been reported in Barrett's oesophagus with intestinal metaplasia alone or with low grade dysplasia, ${ }^{12}{ }^{26}$ suggesting that this may be a relatively early event in the progression to adenocarcinoma. Increased p21 expression is also found in Barrett's oesophagus scored indefinite for dysplasia or low grade dysplasia compared with intestinal metaplasia alone, again suggesting that this is an early event. ${ }^{14}$ p27 expression increases in dysplastic Barrett's oesophagus compared with metaplasia, but it is inactivated in adenocarcinoma, and its loss is associated with a poor outcome. ${ }^{15}$ Cyclin Dl expression is also common in Barrett's oesophagus without dysplasia, and is associated with a higher risk of malignant progression. ${ }^{16}$ Finally, overexpression of the protooncogene c-erbB2 may be an early event because it has been described in intestinal metaplasia, dysplasia, and adenocarcinoma. ${ }^{18}$

In our present study, we have examined cell cycle markers in tissue samples from patients with intestinal metaplasia in the lower oesophagus and a range of controls. As anticipated, little proliferative activity was seen in patients with a normal SCJ. The presence of inflammation was associated with an increase in Ki67, indicating increased cellular proliferation and a modest increase in cell cycle regulators: p53, p21, and p27. Within these groups, an association was seen between p27 and cyclin D1. This is perhaps not surprising because p27 controls cyclin Dl activity by complexing with it, thereby inhibiting cell cycle associated kinase activity.

In patients with Barrett's oesophagus, increased expression of c-erbB2 was apparent without an increase in proliferative markers. This unexpected finding can be explained in part by the fact that most of the patients with Barrett's oesophagus were taking proton pump inhibitors at the time of their endoscopy. Intermittent exposure to acid has been shown to promote proliferation and reduce differentiation in Barrett's oesophagus cell cultures, ${ }^{27}$ and effective acid suppression, judged by 24 hour $\mathrm{pH}$ monitoring, has been shown to reduce proliferative activity in patients with Barrett's oesophagus..$^{28}$

Table 2 Marker expression in the six study groups

\begin{tabular}{lllllll}
\hline Marker & $\begin{array}{l}\text { Normal SCJ no } \\
\text { inflammation }\end{array}$ & $\begin{array}{l}\text { Normal SCJ with } \\
\text { inflammation }\end{array}$ & BO & OAC & SSBO & IMNSCJ \\
\hline p21 & $0.3(0-1 ; 25 \%)$ & $0.6(0-2 ; 57 \%)$ & $0.3(0-1 ; 25 \%)$ & $0.8(0-2 ; 58 \%)$ & $0.6(0-2 ; 50 \%)$ & $0.5(0-2 ; 43 \%)$ \\
p27 & $0.4(0-1 ; 42 \%)$ & $0.6(0-1 ; 64 \%)$ & $0.3(0-1 ; 25 \%)$ & $1.1(0-2 ; 92 \%)$ & $0.7(0-2 ; 60 \%)$ & $1.0(0-2 ; 71 \%)$ \\
p53 & $0.1(0-1 ; 8 \%)$ & $0.2(0-1 ; 21 \%)$ & $0.1(0-1 ; 8 \%)$ & $1.5(0-3 ; 67 \%)$ & $0.4(0-1 ; 40 \%)$ & $0.5(0-2 ; 43 \%)$ \\
Ki67 & $0.4(0-1 ; 42 \%)$ & $0.9(0-2 ; 71 \%)$ & $0.3(0-1 ; 25 \%)$ & $1.5(0-3 ; 83 \%)$ & $0.6(0-1 ; 60 \%)$ & $0.6(0-1 ; 57 \%)$ \\
Cyclin D1 & $0.5(0-1 ; 50 \%)$ & $0.5(0-2 ; 36 \%)$ & $0.3(0-2 ; 18 \%)$ & $0.7(0-2 ; 58 \%)$ & $0.4(0-1 ; 40 \%)$ & $1.0(0-2 ; 79 \%)$ \\
c-erbB-2 & $0.5(0-2 ; 42 \%)$ & $0.5(0-1 ; 46 \%)$ & $0.9(0-2 ; 67 \%)$ & $1.2(0-3 ; 64 \%)$ & $0.7(0-2 ; 50 \%)$ & $0.8(0-2 ; 62 \%)$ \\
\hline
\end{tabular}

Mean score (range; percentage + or more)

$\mathrm{BO}$, Barrett's oesophagus; IMNSCJ, intestinal metaplasia at a normal squamo-columnar junction; OAC, oesophageal adenocarcinoma; SCJ, squamo-columnar junction; SSBO, short segment Barrett's oesophagus. 


\section{Take home messages}

- Oesophageal adenocarcinoma is associated with deregulation of the cell cycle and the control of apoptosis

- Although the proposed aetiologies of short segment Barrett's oesophagus (gastro-oesophageal reflux) and intestinal metaplasia at a normal squamo-columnar junction (IMNSCJ) (Helicobacter pylori infection) differ, the cell cycle response appears to be similar, and both may have malignant potential

- Cyclin D1 expression was increased in patients with IMNSCJ, and this is probably related to the associated $H$ pylori infection

In patients with adenocarcinoma, high c-erbB2 expression was associated with increased proliferative markers and loss of cell cycle control, and these results broadly parallel previously published data. ${ }^{14} 151726$

With the exception of cyclin D1, marker expression in patients with SSBO and IMNSCJ was similar, and the expression of c-erbB2 was similar to that seen in patients with Barrett's oesophagus. However, in patients with IMNSCJ ( $H$ pylori associated intestinal metaplasia), there was a pronounced increase in expression of the potential oncogene, cyclin D1, and this appeared to be associated with upregulation of its inhibitor, p27. Others have also suggested that $H$ pylori may activate cyclin D $1 .^{30}$ In patients with SSBO, although cyclin D1 expression was not increased, p27 appeared to be upregulated. Furthermore, within both groups, cyclin D1 and c-erbB2 were associated and paralleled the expression of both p53 and p21. It is possible that external factors are stimulating metaplastic cells to proliferate, and mutations to genes controlling the cell cycle, such as p53, may subsequently result in the development of dysplasia and adenocarcinoma.

We appreciate that our study has limitations. First, we recognise that our patient classifications are based on the histological finding of intestinal metaplasia in relatively small biopsy samples. We realise that metaplasia can be patchy and sampling error may have led us to classify patients with patchy SSBO as normal, thereby minimising the differences between the two groups. Second, the numbers studied were relatively small, limiting the power of our conclusions. Further studies are clearly indicated.

In conclusion, the results of our present study have shown that oesophageal adenocarcinoma is associated with deregulation of the cell cycle and apoptotic control. With the exception of cyclin Dl, expression of the markers studied in IMNSCJ and SSBO was similar, and c-erbB2 expression was comparable to that seen in Barrett's oesophagus. An increase in cyclin Dl expression in apparent in patients with IMNSCJ, and probably relates to the associated $H$ pylori infection. We feel that although the proposed aetiologies of SSBO (gastro-oesophageal reflux) and IMNSCJ (H pylori infection) differ, the cell cycle response appears to be similar, and both may have malignant potential.

\section{ACKNOWLEDGEMENTS}

We are grateful to Mrs B Smith and Dr I Brock for technical assistance, Dr X Lu for the p27 antibody, and the research committee of the Northern General Hospital and Yorkshire Cancer Research for financial sponsorship.

\section{Authors' affiliations}

N J Trudgill, S A Riley, Department of Gastroenterology, Northern General Hospital, Sheffield S5 7AU, UK

S K Suvarna, Department of Histopathology, Northern General Hospital J A Royds, University of Otago, New Zealand

\section{REFERENCES}

1 Powell J, McConkey CC. Increasing incidence of adenocarcinoma of the gastric cardia and adjacent sites. Br J Cancer 1990;62:440-3.

2 Blot WJ, Devesa SS, Kneller RW, et al. Rising incidence of adenocarcinoma of the esophagus and gastric cardia. J Am Med Assoc 1991;265:1287-9.

3 Haggitt RC, Tryzelaar J, Ellis FH, et al. Adenocarcinoma complicating columnar epithelium-lined (Barrett's esophagus). Am J Clin Pathol 1978;70:1-5.

4 Reid BJ, Blount PL, Rubin CE, et al. Flow cytometric and histological progression to malignancy in Barrett's esophagus: prospective endoscopic surveillance of a cohort. Gastroenterology 1992;102:1212-19.

5 Spechler SJ, Zeroogian JM, Antonioli DA, et al. Prevalence of metaplasia at the gastro-oesophageal junction. Lancet 1994;344:1533-6.

6 Trudgill NJ, Suvarna SK, Kapur KC, et al. Intestinal metaplasia at the squamocolumnar junction in patients attending for diagnostic gastroscopy Gut 1997;41:585-9

7 Hackelsberger A, Gunther T, Schultze V, et al. Intestinal metaplasia at the gastro-oesophageal junction: Helicobacter pylori gastritis or gastrogastro-oesophageal junction: Helicobacter pylori gas

8 Schnell TG, Sontag SJ, Chejfec G. Adenocarcinomas arising in tongues or short segments of Barrett's esophagus. Dig Dis Sci 1992;37:137-43.

9 Hirota WK, Loughney TM, Lazas DJ, et al. Specialized intestinal metaplasia, dysplasia and cancer of the esophagus and esophagogastric junction: prevalence and clinical data. Gastroenterology 1999; 116:277-85.

10 Sharma P, Morales TG, Bhattacharyya A, et al. Dysplasia in short-segment Barrett's esophagus: a prospective 3-year follow up. Am J Gastroentero 1997;92:2012-16.

11 Weston AP, Krmpotich PT, Cherian R, et al. Prospective long-term endoscopic and histological follow-up of short segment Barrett's oesophagus: comparison with traditional long segment Barrett's oesophagus. Am J Gastroenterol 1997;92:407-13.

12 Casson AG, Manolopoulos B, Troster M, et al. Clinical implications of p53 gene mutation in the progression of Barrett's epithelium to invasive esophageal cancer. Am J Surg 1994;167:52-7.

13 Jones DR, Davidson AG, Summer CL, et al. Potential application of p53 as an intermediate biomarker in Barrett's esophagus. Ann Thorac Surg 1994;57:598-603.

14 Hanas JS, Lerner MR, Lightfoot SA, et al. Expression of the cyclin-dependent kinase inhibitor p21wafl/cipl and p53 tumor suppressor in dysplastic progression and adenocarcinoma in Barrett esophagus. Cancer 1999:86:756-63.

15 Singh SP, Lipman J, Goldman H, et al. Loss or altered subcellular localization of p27 in Barrett's associated adenocarcinoma. Cancer Res 1998; 58:1730-5

16 Bani-Hani K, Martin IG, Hardie L, et al. Prospective study of cyclin D1 overexpression in Barrett's esophagus: association with increased risk of adenocarcinoma. J Natl Cancer Inst 2000;92:1316-21.

17 Hong MK, Laskin WB, Herman BE, et al. Expansion of the Ki-67 proliferative compartment correlates with degree of dysplasia in Barrett's esophagus. Cancer 1995;75:423-9.

18 Jankowski J, Coghill G, Hopwood D, et al. Oncogenes and onco-suppressor gene in adenocarcinoma of the oesophagus. Gut 1992;33:1033-8.

19 Gulizia JM, Wang H, Antonioli D, et al. Proliferative characteristics of intestinalized mucosa in the distal esophagus and gastroesophageal junction (short segment Barrett's esophagus): a case control study. Hum Pathol 1999;30:412-18.

20 Morson BC, Belcher JR. Adenocarcinoma of the oesophagus and ectopic gastric mucosa. Br J Cancer 1952;6:127-30.

21 Mueller J, Werner M, Siewert JR. Malignant progression in Barrett's esophagus: pathology and molecular biology. Recent Results Cancer Res 2000;155:29-41.

22 El-Diery WS, Tokino T, Velculescu VE, et al. WAF1, a potential mediator of tumor suppression. Cell 1993:75:817-25.

23 Pagano M, Tam SW, Theodoras AM, et al. Role of the ubiquitin-proteasome pathway in regulating abundance of the cyclin-dependent kinase inhibitor p27. Science 1995;269:682-5.

24 Arber N, Lightdale C, Rotterdam H, et al. Increased expression of the cyclin Dl gene in Barrett's esophagus. Cancer Epidemiol Biomarkers Prev 1996:5:457-9.

25 Yamamoto T, lkawa S, Akiyama T, et al. Similarity of protein encoded by the human c-erbB-2 gene to epidermal growth factor receptor. Nature 1986:319:230-4.

26 Younes $M$, Lebovitz RM, Lechago LV, et al. p 53 protein accumulation in Barrett's metaplasia, dysplasia and carcinoma: a follow-up study. Gastroenterology 1993;105:1637-42.

27 Fitzgerald RC, Omary MB, Triadafilopoulos G. Dynamic effects of acid on Barrett's esophagus. An ex vivo proliferation and differentiation model. J Clin Invest 1996:98:2120-8.

28 Ouatu-Lascar R, Fitzgerald RC, Triadafilopoulos G. Differentiation and proliferation in Barrett's esophagus and the effects of acid suppression. Gastroenterology 1999;117:327-35. 
29 Peters FTM, Ganesh S, Kuipers EJ, et al. Effect of elimination of acid reflux on epithelial cell proliferative activity of Barrett's esophagus. Scand J Gastroenterol 2000;35:1238-44.
30 Hirata Y, Maeda S, Mitsuno Y, et al. Helicobacter pylori activates cyclin D1 gene through mitogen activated protein kinase pathway in gastric cells. Infect Immun $2001 ; 69: 3965-71$.

\section{$\mathrm{ECHO}$}

\section{Toxins are linked to cancer of the bile duct}

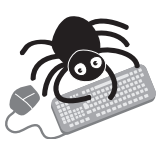

Please visit the Molecular Pathology website [www. molpath.com] for a link to the full text of this article.
T

he first study to test for DNA adducts as a marker for intrahepatic cancer of the bile duct

has lent more support to the hypothesis that toxins damaging DNA lead to cancer.

Greater exposure to environmental toxins may explain the rapid rise in deaths from this cancer in Western countries over the past 30 years, suggest the authors.

Patients with the cancer had more DNA adducts in samples of their tumour or adjacent to their tumour than patients without (median relative amounts/ $10^{8}$ nucleotides: tumour DNA 7.2 (range 1.8-48.4); tumour adjacent DNA 8.6 (1.2-51.6) v non-cancer DNA 2.9 (0.611.5)). The pattern and density of DNA adducts differed between tumour DNA and tumour adjacent DNA and between each of these and non-cancer DNA.

Tumour tissue was taken from 32 men with primary intrahepatic cholangiocarcinoma and tumour adjacent tissue from 28 of them. Cystic ducts were obtained from seven cancer free patients during surgery for gall stones. Adducts were detected in DNA extracted from each sample by ${ }^{32} \mathrm{P}$ postlabelling assays, TLC separation, and autoradiography. Positive and negative controls were included.

DNA adducts are modified DNA bases formed when electrophilic carcinogens or their metabolites bind to DNA. They are key to chemically induced mutagenesis through misrepair or absence of repair and are markers for chemical mutagenesis, but not hitherto in bile duct tissue, even though the liver and biliary system metabolise carcinogens. Intrahepatic bile duct cancer is the second commonest liver cancer worldwide, but the cause of its prominence is unknown.

$\Delta$ Gut 2003;52:586-591 